\title{
PENGARUH LINGKUNGAN BISNIS TERHADAP USAHA KECIL DAN MENENGAH DI JAWA TIMUR
}

\author{
Lukman \\ Ikatan Sarjana Ekonomi Indonesia \\ lukman@yahoo.com
}

\begin{abstract}
This research aims to analyze: indicators that can be explained in a timely and consistent in measuring environmental business area, invalid constructs influences and contributions to the business environment of SMES, good size variansi is not made directly to it. The Data used in this research is data cross section of the County/city in East Java on priode in 2010, which is sourced from the secondary data KPPOD and BPPS. An analysis using Structural Equation Model approach. With the method of least square estimation of weight (WLS) and processed with LISREL program Student. Research results show that the area of business environment indicators precise and consistent in explaining the business environment is kostruk security and resulusi conflicts, transaction costs in the area, access to land and business assurance efforts, licensing business, the management of infrastructure in the area, local government interactions with businessmen.
\end{abstract}

Keywords: Business Environment; SMEs; Structural Equation Model

\author{
Abstrak \\ Kata Kunci: Lingkungan Bisnis; UMKM; Model Persamaan Struktural
}




\section{PENDAHULUAN}

Usaha kecil dan menengah (UKM) merupakan salah satu kekuatan pendorong terdepan dalam pembangunan ekonomi. Gerak sektor UKM sangat vital untuk menciptakan pertumbuhan dan lapangan pekerjaan. UKM cukup fleksibel dan dapat dengan mudah beradaptasi dengan pasang surut dan arah permintaan pasar. mereka juga menciptakan lapangan pekerjaan lebih cepat dibandingkan sektor usaha lainnya, dan mereka juga cukup terdiversifikasi dan memberikan kontribusi penting dalam ekspor dan perdagangan.

Hanafi (2004) dalam Robinson mengistilahkan lingkungan bisnis menjadi lingkungan eksternal dengan lingkungan umum/makro. Lingkungan umum/makro mencakup kondisi yang mungkin mempunyai dampak terhadap perusahaan, namun relevansinya tidak sedemikian jelas. Sementara itu, Huner dan Wheelen (2000) menjelaskan karakteristik lingkungan ektternal merupakan variabel-variabel yang berada diluar perusahaan yang terdiri dari dua bagian task environment (lingkungan individual mikro), dan social environment (lingkungan umum makro). Task environment adalah semua elemen-elemen yang secara langsung mempengaruhi operasi utama perusahaan. Social environment adalah sebagaian besar kekuatan-kekuatan umum yang tidak langsung mempengaruhi aktivitas jangka pendek, akan tetapi dapat dan bahkan mempengaruhi keputusan jangka panjang. Berkaitan dengan karakteristik lingkungan eksternal menurut $\mathrm{Hiz}$, at all (2001), merupakan semua faktor yang terkait dengan kondisi diluar perusahaan yang sulit dikendalikan.

Banyaknya usaha kecil dan menengah sebagai salah satu sumber munculnya entrepreneur harus didorong dan diberikan sebuah lingkungan yang mendukung perkembangannya, karenanya UKM memiliki potensi besar sebagai penyumbang GDP. Di negara maju, $60 \%$ GDP bersumber dari usaha kecil dan menengah ini, seperti pendapat Aslund dan Johnson (2003) : Small enterprises are of critical importance to the functioning of an economy and thus economic development. In developed OECD economies, about 60 percent of GDP is generated by small enterprises, i.e., enterprises 
with a maximum of 50 employees (OECD 2002). Selain itu, menurut De Soto (Jhonson and Aslund, 2003) dari hasil studi empirisnya, kelemahan pembangunan perekonomian dari negara semi maju, seperti Amerika Latin atau negara bekas komunis, karena sedikitnya usaha kecil dan menengah di negara tersebut.

Usaha Kecil dan Menengah (UKM) di Indonesia sangat besar (BPS Jakarta), bahwa industri besar hanya berjumlah 0,77 persen dengan jumlah tenaga kerja sebesar 9,63 persen, sedangkan industri menengah, kecil dan mikro dengan persentase yang sangat tinggi masing-masing dengan jumlah usaha sebesar 2,90 persen, 63,07 persen dan 33,26 persen serta jumlah tenaga kerja sebesar 6,17 persen, 21,45 persen dan 62,76 persen. Besarnya jumlah UKM memiliki peluang maupun tantangan yang besar, peluang bagi sumber kehadiran entrepreneur sebagai salah satu syarat pembangunan ekonomi. Tambunan (1999) menyatakan bahwa langkah pengembangan industri kecil dan menengah menjadi harapan peningkatan perekonomian daerah dan nasional, hal ini dikarenakan secara kualifikasi, fungsi makro yang diperankan oleh usaha kecil dalam perekonomian nasional cukup signifikan, yakni: 1) Usaha kecil memperkokoh perekonomian nasional melalui fungsi pemasok fungsi produksi, fungsi penyalur dan pemasar bagi hasil produk-produk industri besar. 2) Usaha kecil dapat meningkatkan efisiensi ekonomi, khususnya dalam menyerap sumber daya yang ada. 3) Usaha kecil yang dipandang sebagai sarana pendistribusian pendapatan nasional, alat pemerataan dalam berusaha dan pemerataan dalam pendapatan, maka pengembangan dan kebijakan yang mengarah pada tumbuh dan berkembangnya UKM harus didorong.

Mencermati fenomena dan permasalahan lingkugan bisnis dan ukuran UKM yang ditunjukan dengan kondisi lingkungan bisnis yang masih rendah yakni masih dibawah skor 70 (KPPOD), sedangkan jumlah UKM dengan konsentrasi di jawa yang ditandai indeks konsentrasi dan loqation quation lebih dari 1(BPS) dan kemiskinan di jawa yang masih diatas ratarata nasionalnya. 
Kerangka Pemikiran ini merujuk pada penelitian yang telah dilakukan oleh Beck, Kunt, and Levine yaitu tentang 'Small and Medium Enterprises, Growth, and Poverty : Cross-Country Evidence untuk hubungan antara lingkungan bisnis dan kemiskinan serta hubungan UKM dengan kemiskinan; dan Schiffer and Weder dalam Firm Size and the Business Environment: Worldwide Survey yang menghubungkan antara lingkungan bisnis dengan UKM. Adapun indikator lingkungan bisnis yang digunakan menggunakan indikator proses dengan tidak menyertakan indicator endowment yang ada ditiap daerah. Indikator ini dikembangkan dari variabel lingkungan bisnis yang digunakan oleh Beck, Kunt, and Levine; Mirjam dan Weder juga dari Ayyagari, Beck, Kunt dalam Small and Medium Enterprises across the Globe serta KPPOD dalam local economic governance in Indonesia yaitu (1) akses terhadap lahan usaha dan kepastian usaha, (2) perizinan usaha, (3) interaksi pemda dengan pelaku usaha, (4) program pengembangan usaha, (5) kapasitas dan integitas bupati/walikota, (6) biaya transaksi di daerah, (7) pengelolaan infrastruktur di daerah, (8) keamanan dan resolusi konflik, (9) peraturan daerah.

\section{METODE}

Dalam Model Pengaruh Lingkungan Bisnis terhadap ukuran Industri Kecil dan Menengah menggunakan pendekatan structural equatiom model (SEM) dengan menggunakan 11 variabel teramati dan 3 variabel laten. Dari kerangka teori pada bab dua maka hubungan tersebut dapat dibuat path diagram: Lingkungan Bisnis, Usaha Kecil dan Menengah pada Gambar 1.

Path diagram tersebut terbagi manjadi dua bagian variabel yakni variabel eksogen yakni berisi lingkungan bisnis yang dijelaskan oleh sembilan indikator yakni (1) akses terhadap lahan usaha dan kepastian usaha, (2) perizinan usaha, (3) interaksi pemda dengan pelaku usaha, (4) program pengembangan usaha, (5) kapasitas dan integitas bupati/walikota, (6) biaya transaksi di daerah, (7) pengelolaan infrastruktur di daerah, (8) keamanan dan resolusi konflik, (9) peraturan daerah. Sedangkan variabel endogen terdiri dari dua yakni (1) ukuran usaha kecil dan menengah yang 
dijelaskan oleh share tenaga kerja UKM terhadap total angkatan kerja serta. (2) jumlah penduduk miskin yang dijelaskan oleh presentase penduduk miskin. Penelitian ini dilakukan dalam lingkup Regional untuk tahun 2010. Unit analisisnya adalah 25 kabupaten/kota di Jawa Timur.

Gambar 1.

\section{Diagram Jalur hubungan Lingkungan Bisnis terhadap Ukuran Industri} Kecil dan Menengah dan dampaknya terhadap Kemiskinan
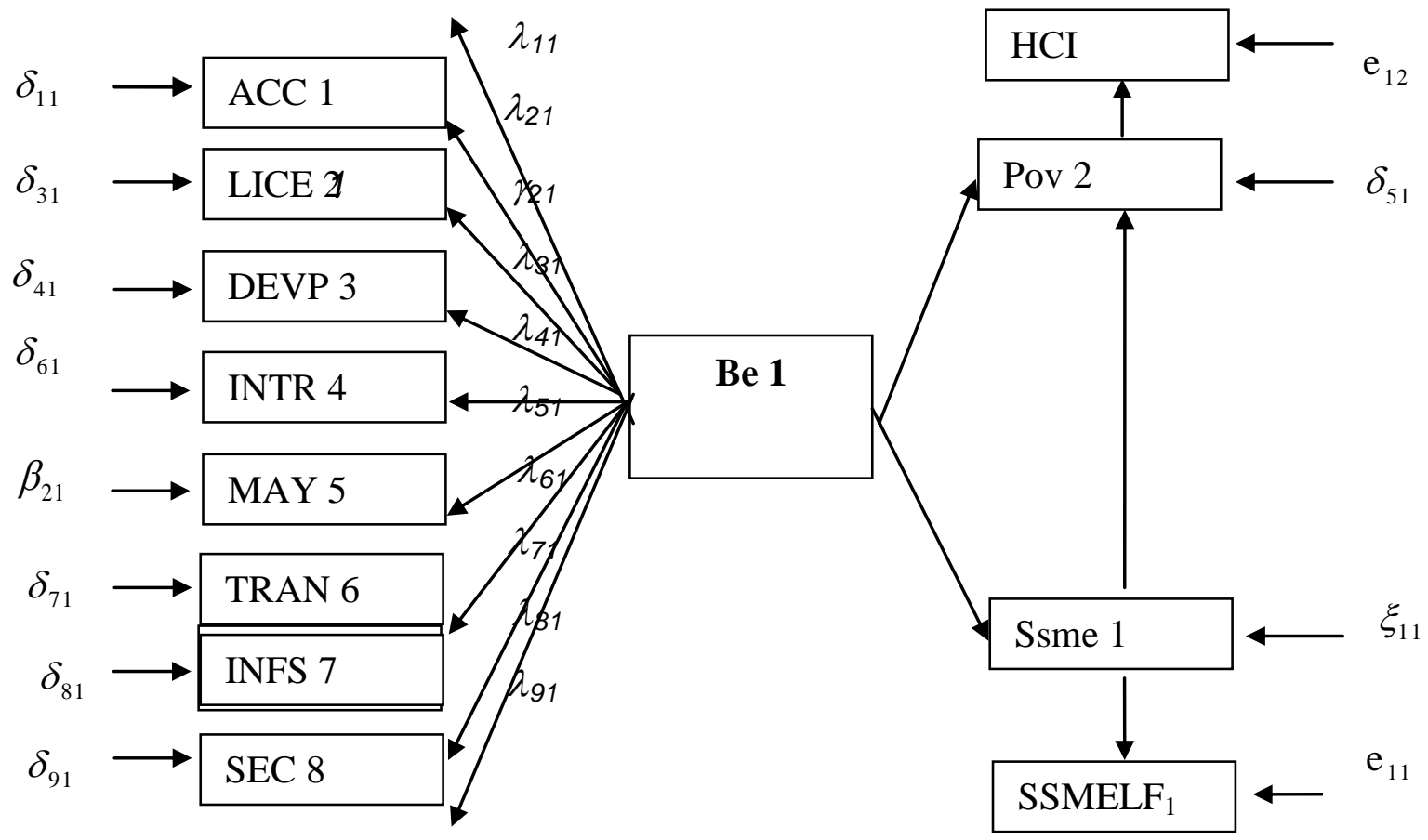

Metode yang digunakan adalah Struktural Equation Model (SEM) dengan bantuan program komputer LISREL 8.8. SEM adalah suatu teknik modeling statistik yang bersifat cross-sectional, linear dan umum. Dari setiap kasus, suatu seri variabel dikaitkan dengan suatu teknik analisis faktor (factor analysis), analisis jalur (path analysis) dan regresi (regression) (seperti regresi berganda) dan hasilnya (resultant output) dipelajari/dikaji mengenai signifikansi statistiknya (statistical significant). 


\section{HASIL DAN PEMBAHASAN}

Lingkungan bisnis kabupaten / kota di Jawa rata-rata belum menunjukkan kinerja yang baik seperti terlihat pada rata-rata hitung sebagaimana ditunjukkan oleh Table 4.1 dari masing-masing indicator lingkungan bisnis. Lingkungan bisnis masih memiliki nilai indeks yang cukup rendah yakni masih di bawah 70 adalah indeks perizinan usaha (60.19), indeks interaksi Pemda dengan pelaku usaha (52.947), indeks program pengembangan usaha (41.74), indeks kapasitas dan integritas bupati/walikota (54.965), indeks keamanan dan resolusi konflik (59.762). sedangkan yang telah memiliki nilai rata-rata cukup baik yakni berada di atas 70 adalah indeks Akses Terhadap Lahan Usaha dan Kapasitas Usaha (71.345), indeks biaya transaksi di daerah (70.096), indeks infrastruktur daerah (73.824) dan indeks peraturan daerah (85.751).

Tabel 1. Rata-rata Hitung Indikator Lingkungan Bisnis

\begin{tabular}{|c|c|c|c|}
\hline INDIKATOR & $\begin{array}{c}\text { RATA- } \\
\text { RATA } \\
\text { HITUNG }\end{array}$ & $\begin{array}{l}\text { Nilai } \\
\text { Tertinggi }\end{array}$ & $\begin{array}{c}\text { Nilai } \\
\text { Terendah }\end{array}$ \\
\hline $\begin{array}{l}\text { Akses terhadap lahan usaha dan kepastian } \\
\text { Usaha, (ACC) }\end{array}$ & 71.345 & 93.90 & 39.70 \\
\hline Perizinan Usaha, (LICE) & 60.19 & 84.60 & 37.60 \\
\hline $\begin{array}{l}\text { Interaksi Pemda dengan pelaku usaha, } \\
\text { (INTR) }\end{array}$ & 52.947 & 70.20 & 26.30 \\
\hline Program Pengembangan Usaha, (DEVP) & 41.74 & 86.50 & 15.00 \\
\hline $\begin{array}{l}\text { Kapasitas dan Integritas Bupati/Walikota, } \\
\text { (MAY) }\end{array}$ & 54.965 & 83.40 & 27.10 \\
\hline Biaya Transaksi di Daerah, (TRAN) & 70.096 & 93.00 & 42.20 \\
\hline Pengelolaan Infrastruktur di Daerah, (INFS) & 73.824 & 89.00 & 57.20 \\
\hline Keamanan dan Resolusi Konflik, (SEC) & 59.762 & 96.70 & 31.20 \\
\hline Peraturan Daerah, (REG) & 85.751 & 93.20 & 31.40 \\
\hline
\end{tabular}

Sumber : Data diolah, 2010 
Indeks akses lahan usaha dan kepastian usaha memiliki nilai tertinggi sebesar 93.90 dan terendah sebesar 39.70. Jawa Timur 5 ranking tertinggi adalah Kota Surabaya, Kabupaten Sampang, Kabupaten Bangkalan, Kabupaten Gresik, Kota Pasuruan. Sementara itu, lima ranking terendah adalah Kabupaten Bondowoso, Kabupaten Kediri, Kabupaten Banyuwangi, Kabupaten Tuban, Kabupaten Situbondo.

Indeks perizinan usaha memiliki nilai tertinggi sebesar 84.60 dan terendah sebesar 37.60. Jawa Timur 5 rangking tertinggi adalah Kabupaten Malang, Kota Surabaya, Kota Malang, Kabupaten Bojonegoro, Kabupaten Gresik. Dan lima ranking terendah adalah Kabupaten Bondowoso, Kabupaten Sidoarjo, Kabupaten Pacitan, Kabupaten Lumajang, Kota Blitar.

Indeks interaksi pemda dengan pelaku usaha memiliki nilai tertinggi sebesar 70.20 dan terendah sebesar 26.30. sedangkan 5 ranking tertinggi Jawa Timur 5 rangking tertinggi adalah Kota Probolinggo, Kota Blitar, Kabupaten Magetan, Kabupaten Pacitan, Kota Kediri dan lima ranking terendah adalah Kota Malang, Kabupaten Bojonegoro, Kabupaten Kediri, Kota Pasuruan, Kabupaten Sumenep.

Indeks program pengembangan usaha memiliki nilai tertinggi sebesar 86.50 dan terendah sebesar 1500 . Sedangkan 5 ranking tertinggi di Jawa Timur 5 ranking tertinggi adalah Kota Blitar, Kota Probolinggo, Kabupaten Gresik, Kota Madiun, Kota Pasuruan dan lima ranking terendah adalah Kabupaten Lamongan, Kabupaten Malang, Kabupaten Tulungagung, Kabupaten Sumenep, Kabupaten Kediri.

Indeks kapasitas dan integritas bupati/walikota memiliki nilai tertinggi sebesar 83.40 dan terendah sebesar 27.10. sedangkan 5 ranking tertinggi di Jawa Timur 5 ranking tertinggi adalah Kota Probolinggo, Kota Blitar, Kabupaten Lumajang, Kabupaten Bangkalan, Kabupaten Lamongan dan lima ranking terendah adalah Kabupaten Situbondo, Kota Malang, Kota Surabaya, Kota Pasuruan, Kabupaten Sumenep.

Indeks Biaya Transaksi di Daerah memiliki nilai tertinggi sebesar 93.00 dan terendah sebesar 42.20. sedangkan 5 ranking tertinggi di Jawa Timur 5 ranking tertinggi adalah Kabupaten Magetan, Kabupaten Pamekasan, 
Kabupaten Tulungagung, Kabupaten Tuban, Kabupaten Pacitan dan lima ranking terendah adalah Kota Mojokerto, Kabupaten Bojonegoro, Kota Surabaya, Kota Blitar, Kabupaten Jombang.

Indeks pengelolaan infrastruktur di daerah memiliki nilai tertinggi sebesar 89.00 dan terendah sebesar 57.20 . sedangkan 5 ranking tertinggi di Jawa Timur 5 ranking tertinggi adalah Kabupaten Tuban, Kabupaten Magetan, Kota Kediri, Kabupaten Kediri, Kabupaten Madiun dan lima ranking terendah adalah Kabupaten Pemekasan, Kabupaten Bangkalan, Kabupaten Trenggalek, Kabupaten Pacitan, Kabupaten Sampang.

Indeks keamanan dan resolusi konflik memiliki nilai tertinggi sebesar 96.70 dan terendah sebesar 31.20. sedangkan 5 ranking tertinggi di Jawa Timur 5 ranking tertinggi adalah Kabupaten Pemakasan, Kabupaten Trenggalek, Kabupaten Pacitan, Kabupaten Magetan, Kabupaten Tuban dan lima ranking terendah adalah Kota Pasuruan, Kabupaten Probolinggo, Kabupaten Jember, Kota Surabaya, Kabupaten Jombang.

Ukuran usaha kecil dan menengah dalam penelitian ini diukur dari share tenaga kerja yang bekerja pada skala usaha kecil dan menegah terhadap total angkatan kerja daerah. Atau secara matematis dapat dirumuskan sebagai berikut :

Ukuran Usaha Kecil dan Menengah $=\frac{\Sigma T_{\text {Tenaga kerja UKM }}}{\sum \text { AngkatanKerja }}$

Berdasarkan hasil penghitungan data tahun 2010 diperoleh beberapa ukuran statistik yang dapat memberikan informasi secara deskriptif karakteristik ukuran usaha kecil dan menengah di masing-masing kabupaten / kota di Jawa dan tahun 2006.

Tabel 2. Ukuran Statistik Variabel Ukuran Usaha Kecil dan Menengah

\begin{tabular}{lc}
\hline \multicolumn{1}{c}{ Ukuran Statistik } & Ukuran UKM \\
\hline Rata-rata hitung & 13.57 \\
Maksimum observasi & 34.70 \\
Minimum observasi & 4.06 \\
\hline
\end{tabular}

Sumber : Data diolah, 2010 
Ukuran usaha kecil dan menengah tertinggi sebesar 34.70 dan terendah pada tahun 2006 sebesar 4.06. sedangkan ukuran Usaha Kecil dan Menengah di Provinsi Jawa Timur, ukuran usaha kecil dan menengah tertinggi di Kota Blitar, Kota Mojokerto, Kota Pasuruan, Kota Madiun, Kota Malang dan terendah di Kabupaten Sumenep, Kabupaten Pacitan, Kabupaten Pamekasan, Kabupaten Sampang.

Lingkungan Bisnis Daerah yang diukur dari indeks pengelolaan ekonomi daerah ataupun iklim usaha daerah yang digunakan oleh KPPOD maupun Doing Business Index dari the International Finance Corporation/World Bank (and its sub-national counterparts), juga dalam the Worldwide Governance Indicators and the subnational economic governance indices oleh The Asia Foundation di Vietnam, Philippines, Combadia, and Sri Lanka terdiri dari indeks akses terhadap lahan usaha dan kepastian usaha, indeks perizinan usaha, indeks interaksi pemerintah daerah dengan pelaku usaha, indeks program pengembangan usaha, indeks kapasitas dan integritas bupati/walikota, indeks keamanan dan resolusi konflik, indeks akses terhadap lahan usaha dan kepastian usaha, indeks biaya transaksi di daerah, indeks infrastruktur daerah dan indeks peraturan daerah. Terdapat 3 indikator yang kurang tepat dan konsisten menjelaskan konstruk lingkungan bisnis, yakni peraturan daerah, kapasitas bupati/waliko, program Pemberdayaan / pengembangan usaha.

Masing-masing indikator yang tepat dan konsisten menjelaskan konstruk lingkungan bisnis adalah keamanan dan resolusi konflik dengan loading factor sebesar 0.76 dan bertanda positif, dan biaya transaksi di daerah dengan loading factor 0.76 bertanda positif. Hal ini menandakan bahwa kedua faktor ini sangat kuat sebagai indikator penjelas lingkungan bisnis daerah. Berikutnya Akses terhadap lahan usaha dan kepastian usaha dengan loading factor 0.66 bertanda positif, factor izin usaha dengan loading factor 0.64 bertanda positif, factor infrastruktur daerah bertanda positif dengan loading factor sebesar 0.58 , hal ini menandakan bahwa empat indikator ini menjadi penjelas yang cukup besar pula demi membangun lingkungan bisnis. 
Hasil penelitian ini berbeda dengan hipotesis awal bahwa lingkungan bisnis berhubungan positif terhadap ukuran usaha kecil dan menengah. Artinya bahwa lingkungan bisnis belum menjadi pendorong bagi tumbuhnya UKM tetapi justru menjadi pendorong bagi perusahaan besar. Alasannya adalah bahwa, sebagaimana alasan pada pengaruh lingkungan bisnis terhadap kemiskinan, menyebabkan beban UKM lebih besar dibandingkan dengan beban usaha besar. Hal lain yang menjadikan lingkungan bisnis berhubungan negative adalah kinerja keamanan dan ketertiban umum yang semakin baik, membawa penggusuran-penggusuran bagi UKM khususnya kaki lima maupun UKM bidang makan minum yang tidak memiliki sertifikat dinas kesehatan.

Badan Pusat Statistik (BPS, 2006) menggolongkan perusahaan/usaha berdasarkan omset per tahun yakni (1) usaha mikro : kurang Rp. 50 juta (2) usaha kecil Rp. 50 juta - I milyar (3) usaha menengah Rp. 1 milyar - 3 milyar (4) lebih dari Rp. 3 milyar, Sedangkan industri pengolahan digolongkan ke dalam empat kategori berdasarkan jumlah pekerja pada perusahaan tersebut tanpa memperhatikan besarnya modal yang ditanam ataupun kekuatan mesin yang digunakan.

Bank Indonesia melalui Surat Keputusan Direktur Bank Indonesia Nomor 31/24/KEP/DIR tanggal 5 Mei 1998 mendefinisikan usaha mikro sebagai unit usaha yang dijalankan oleh rakyat miskin atau mendekati miskin dengan ciri-ciri dimiliki oleh keluarga, menggunakan sumber daya lokal dan teknologinya sederhana, lapangan usahanya mudah dimasuki dan ditinggalkan. Sedangkan usaha menengah adalah usaha yang memiliki asset maksimum Rp. 5 milyar untuk sektor industri manufacturing, dan untuk sektor non industri memiliki kekayaan maksimum Rp 600 juta diluar tanah dan bangunan atau memiliki hasil penjualan tahunan maksimum Rp. 3 milyar pada usaha yang dibiayai.

Mintzberg (1992) dalam Saleh (1994) menjelaskan karakteristik UKM sebagai organisasi yang memiliki sifat entrepreneurship dengan ciri : struktur Mintzberg (1992) dalam Saleh (1994) menjelaskan karakteristik UKM sebagai organisasi yang memiliki sifat entrepreneurship dengan ciri : 
struktur organisasinya sangat sederhana, memiliki karakteristik khas tanpa elaborasi, tanpa sifat yang berlebihan, pembagian kerja yang kendor, hirarki manajer kecil, aktivitas cenderung informal, sedikit menggunakan proses perencanaan, sedikit sekali aktifitas bagi karyawan dan manajer, kurang membedakan aset pribadi dan aset perusahaan, tidak menggunakan sistem akuntansi yang baku dan dalam melakukan investasi bersifat perseorangan.

Lebih jauh lagi Sugianto dalam Coliene (2002) menyatakan karakteristik usaha kecil di Indonesia adalah usahanya lebih bersifat keluarga dan manajemen dikendalikan oleh satu orang yaitu kepala keluarga tetapi justru menjadi keuanggulan karena dikelola secara hati-hati, peralatan dan teknologi sederhana, manajemen dan administrasi keuangan lemah, bersifat konsumtif yaitu sabagian besar laba dikonsumsi, jaminan yang dimiliki tidak mencukupi, tempat tinggal dan tempat usaha menyatu, kesulitan dalam akses pasar secara luas, sulit mengidentifikasi permasalahan yang muncul dalam usaha dan lemahnya informasi terhadap kebijakan pemerintah.

Oleh karena itu, UKM merupakan aspek penting dalam pembangunan ekonomi yang kompetitif. Mereka bergerak dalam kondisi yang amat kompetitif dan ketidakpastian amat dipengaruhi oleh situasi lingkungan bisnis dan ekonomi makro. Hal ini dipertegas oleh Schiffer dan Weder (2003) bahwa lingkungan usaha yang buruk lebih banyak merugikan UKM daripada usaha besar.

Menurut Teori Creative Destruction dari Shumpiter : development / pembangunan diartikan sebagai kenaikan output yang disebabkan oleh inovasi yang dilakukan oleh pengusaha (enterpreneur). Sedangkan syaratsyarat terjadinya inovasi ini yaitu: harus ada calon entrepreneur dalam masyarakat dan harus ada lingkungan sosial, ekonomi, politik dan teknologi (business envorienment) sehingga bisa mendukung inovasi. Dari pengertian ini menunjukkan pentingnya lingkungan bisnis dalam pembangunan sebagai usaha untuk meningkatkan pertumbuhan dan tentu saja pengurangan kemiskinan.

Menurut Ball at.all bila dilihat wilayah operasinya ada 3 macam lingkungan bisnis yakni domestic environment, foregn environment serta international 
environment. Domestik environment adalah semua kekuatan yang dapat dikontrol organisasi yang berada di didalam rumah tangga Negara itu dan mempengaruhi kehidupan dan perkembangan perusahaan. Foreign environment adalah sama dengan lingkungan domestik kecuali keberadaan mereka yang berada dari negara lain. International environment adalah interaksi antara kekuatan lingkungan domestik dan luar atau antara serangkaian kekuatan lingkungan luar. Interaksi dari seluruh variabel bentuk lingkungan bisnis sekaligus dapat menjelaslakan bahwa lingkungan bisnis memiliki peran penting dalam perusahaan

Selain mendefinisikan lingkungan bisnis Beck, Kunt dan Levine (2003) mendefinisikan Institusonal bisnis dengan menggunakan indikator dari lingkungan bisnis yang diambil dari Kaufman, Kraay and Mastruzzi (2003) :Institutional Development is an aggregate indicator of the institutional environment in which firms operate. These include information on voice and accountability in the political system, the quality and consistency of' regulations and regulatory enforcement in the country, political stability, the rule of law, the lack of official corruption, and the effectiveness of government the government bureaucracy.

Hal yang sama pun digunakan oleh Ayyagari, Beck, Kunt (2003) dalam mengukur I ingkungan bisnis dengan menggunakan cost of entry, bankruptcy, cost of contract enforcement, credit registry, labor market regulation, Property Rights, Institutional development ( voice and accountability, government e ectiveness, regulatory quality, rule of law, political stability and control of corruption). Selain itu Ayyagari, Beck, Kunt (2003) mengunakan factor penghambat pertumbuhan UKM dengan menggunakan indikator : financing obstacle, infrastructure obstacle, Political Instability obstacle, Inflation obstacle, Exchange rate obstacle, street crime obstacle, organized crime obstacle, Taxes and regulation obstacle, corruption obstacle, judiciary obstacle, dan anticompetitive practices obstacl

Menurut Mirjam Schiffer dan Beatrice Weder (2001: 9) ada delapan lingkungan bisnis yang mempengaruhi ukuran perusahaan adalah 
texes and regulation, policy instability, inflation, exchange rate, judiciary, coruption, street crime, organized and anti-competitive practices obstacle Menurut Mirjam Schiffer dan Beatrice Weder (2001: 9) ada delapan lingkungan bisnis yang mempengaruhi ukuran perusahaan adalah texes and regulation, policy instability, inflation, exchange rate, judiciary, coruption, street crime, organized and anti-competitive practices. Fakor lingkungan yang mempengaruhi perkembangan UKM menurut Bank Dunia (2005) dalam Indonesia Policy Briefs, adalah regulasi yang raembebani, pinjaman bersubsidi, perpajakan dan administrasi perpajakan, infrastruktur, kebijakan dalam pebiayaaan mikro, dan pendidikan.

Penelitian ini menganalisis Lingkungan Bisnis dan UKM. UKM merupakan salah satu kontributor PDRB diharapkan sebagai sumber pertumbuhan dan pemerataan pembangunan yang mampu menjadi agen penurunan angka kemiskinan. Sehingga dengan adanya lingkungan bisnis yang baik akan meningkatkan perannya dalam penurunan angka kemiskinan. Kerangka pemikiran Lingkngan Bisnis mempengaruhi Ukuran UKM dan Kemiskinan baik secara langsung maupun tidak langsung.

\section{SIMPULAN}

Indikator lingkungan bisnis daerah yang tepat dan konsisten dalam menjelaskan konstruk lingkungan bisnis adalah indeks keamanan dan resolusi konflik, biaya transaksi di daerah, akses terhadap lahan usaha dan kepastian usaha, perizinan usaha, pengelolaan infrastruktur di daerah, interaksi pemda dengan pelaku usaha. Sedangkan peraturan daerah dan kapasitas, integritas bupati/walikota, serta program Pemberdayaan dan pengembangan usaha kurang tepat dan konsisten dalam menjelaskan konstruk lingkungan bisnis.

Kinerja Lingkungan bisnis daerah yang dibangun untuk mendorong sektor usaha mengalami trade off terhadap kemiskinan. Hal ini disebabkan indikator lingkungan bisnis mendistorsi sektor pertanian dalam hal alih fungsi lahan. 


\section{PUSTAKA ACUAN}

Badan Pusat Statistik. 2008. Analisis Profil Perusahaan Usaha Indonesia Jakarta: CV Nario Sari.

Ball at.all. 2006. International Business: The challenge of Global Competition. Boston: McGaw-Hill.

Djoko, Retnandi dan Soetanto Hadinoto. 2006. Micro Credit Challenge: Cara Efektif Mengatasi Kemisikinan dan Pengangguran di Indonesia. Jakarta: PT Elek Media Komputindo.

Haris, Ferry Pribadi. 2007. Mencari hubungan antara kebijakan moneter dengan kemiskinan dan ketimpangan pendapatan: Kajian menggunakan data regional Indonesia. www.bi.go.id

Hair, at.al. 2006. Multivariate data Analysis. New Jersey: Prentice Hall.

Kusnendi. 2008. Model - model persamaan structural, satu dan multigroup sampel dengan LISREL. Bandung: Alfabeta.

Levine at.all. 2003. Small and Medium Enterprises, Growth, and Poverty : Cross-country Evidence. world bank policy research working paper 3178, December 2003.

Mukras, M.S. 2003. Poverty Reduction through Strenghtening small and Medium Enterprises. Botswana Journal of African Studies vol.17 (2).

Schiffer at.al. 2001. Firm Size and the business Environment: World Wide Survey. Weder International Finance Corporation Discussion paper Number 43 The World Bank Washington, D.C

Sukirno, Sadono. 2006. Ekonomi Pembangunan: Proses, Masalah dan Dasar Kebijakan. Jakarta: Kencana.

Tambunan, Tulus. 1999. Perkembangan Industri Skala Kecil di Indonesia. Jakarta: PT Mutiara Sumber Widya. 